\title{
Cellulosic biorefinery portfolio and diversification: Strategies to mitigate cellulosic biorefinery risks in US Corn Belt
}

\author{
Rajdeep Golecha ${ }^{*}$ \\ Houston, Texas 77498 \\ rajdeep.golecha@gmail.com \\ 5177557880 \\ Jianbang Gan² \\ Professor, Department of Ecosystem Science and Management \\ Texas A\&M University, College Station, TX 77843, USA \\ j-gan@tamu.edu
}

Feb 01, 2016

\begin{abstract}
Several studies have highlighted that one of the largest risks with cellulosic biorefinery investments are year-to-year variability in cellulosic biomass quantity available. Yet, strategies to mitigate these risks in biofuel development are less understood. In the absence of strategies to minimize the impact due to these variations, both biorefineries and farmers venturing into the cellulosic biofuel arena will be significantly exposed. Studies have been done on using engineering approaches, such as biomass pretreatment and storage to address biomass supply variations. Recent studies have provided market structure and contracting strategies to manage biomass supply risks. However, storage, pre-treatment and similar engineering approaches lead to higher costs and has other limitations such as additional infrastructural requirements. There is a gap in understanding the use of feedstock (biomass) diversification and portfolio strategies to mitigate such risks. In this study a portfolio approach is developed and applied to the case of the US Corn Belt, considering various types of cellulosic biomass including corn stover, wheat straw, and switchgrass. It is found that feedstock diversification mitigates up to $40 \%$ of feedstock supply variations, while biorefinery diversification can mitigate up to $70 \%$ of feedstock supply variations although it is constrained by current cropland use patterns in the region. Overall, diversification and portfolio strategies present an effective way for mitigating risks associated with feedstock supply variations.
\end{abstract}

Key words: Cellulosic Biofuel; Diversification; MPT; Corn-Stover 


\section{Cellulosic biorefinery portfolio and diversification: Strategies to mitigate cellulosic biorefinery risks in US Corn Belt}

\section{Introduction}

Approximately half of the world's current biofuel supply comes from corn ethanol produced in the US [1]. Corn ethanol is found to have several disadvantages, including competition with food supply and low benefit in greenhouse gas offsets [2]. To overcome these shortcomings and expand bioenergy supply, many countries have embarked on developing second generation biofuels produced from cellulosic feedstock such as agricultural and forestry residues and perennial grasses [3]. Cellulosic biomass is primarily agricultural waste (e.g., corn stover, sugarcane bagasse, straws, etc.), forestry residues (e.g., sawdust, logging residue, etc.) or energy crops (e.g., switchgrass, elephant grass, short-rotation woody crops, etc.). For instance, the US targets to produce 76 billion litres of biofuels per year by 2022, which will require about 200 million dry tonnes of biomass annually [4], of which the US Corn Belt is by far the largest source of biomass from agricultural residues [5].

Studies have found that a major risk with cellulosic biofuel investments is variability in the annual availability of biomass by $20-30 \%$, as a result of variations in underlying biomass yield [6]. Along with exposure to supply variations, cellulosic biorefineries will face fundamental challenge due to limitations on long-distance transport and long-term storage of biomass [6]. Its low bulk density in mass and energy prevents biomass for being transported over a long distance. As a result, unlike corn ethanol mills, cellulosic biorefineries source biomass locally, which limits their ability to effectively mitigate regional biomass supply constraints [7].

The large annual variability in local feedstock supply coupled with the constraints in long-distance transport and long-term storage of biomass points to the needs for mitigating the adverse impacts of feedstock supply variations on biofuel development. A recent review has provided the importance of managing biomass supply uncertainties and incorporating these uncertainties in modelling biofuel supply chains [8]. In the absence of a feedstock strategy, these supply variations will lead to significant regional supply-demand imbalances that will ultimately impact feedstock price and transform into variability of biorefinery profit or investment risk, hindering the development of a biofuel industry.

Proposed solutions to mitigating supply variations have focused on either engineering options (biomass pre-treatment and storage) or improvements in the design and management of biofuel supply chains. Pre-treatment of biomass using torrefaction, palletisation, and pyrolysis can convert biomass into denser energy carriers and improve its storability and bulk density [9-13]. Biomass storage can offset feedstock supply variations, but long-term storage remains challenging due to health, safety, and technological risks [14]. Furthermore, these engineering approaches will entail additional investments and production costs, and increase the total cost of cellulosic biofuel substantially. 


\section{Cellulosic biorefinery portfolio and diversification: Strategies to mitigate cellulosic biorefinery risks in US Corn Belt}

Various modelling approaches, particularly mathematical programming, have also been used to identify the optimal logistics and management strategies for biofuel supply chains under uncertainties including variability in feedstock supply. Several studies have suggested a stochastic approach for managing biofuel supply chains under demand and price uncertainties [15-17]. Some others have used linear programming based optimization models [18], and a dynamic, spatially explicit, and multi-echelon Mixed Integer Linear Programming framework [19-21] for minimizing variability in biomass supply chains and in making biofuel investment decisions.

A recent study has progressed understanding of market structures and contracting strategies to address large year to year variability in biomass supply. Using Game Theoretic analysis the studies have found that a 'Derisked' supply market structure, where biorefineries maintain a buffer supply region to 'Derisk' again biomass supply shocks, would significantly reduce risk and biomass cost compared with a free market structure [6]. They find that optimizing biomass trade-offs and setting up long term biomass supply contracts between biorefineries and farmers could significantly reduce biomass cost and supply risk [7]. Another study by Dale et.al has proposed using a network of local biomass processing depots (LBPDs) for sustained supply to biorefinery[22].

However, few studies have attempted to examine portfolio strategies to mitigate biomass supply variations. One such option is through diversifying input (feedstock) blend [23]. While the concept of blending raw materials to optimize profit is widely used by the oil and gas industry [24], its applicability in cellulosic biofuel production remains to be evaluated. Further, it is unclear how diversification strategies to develop a cellulosic biofuel business portfolio can minimize risks. This study is intended to shed light on these gaps. The specific objective of this study is to examine the role and strategies of diversification in mitigating biomass supply risk.

A local diversification strategy considering corn stover, wheat straw, and switchgrass is evaluated for US Corn Belt. A modelling framework is developed, to identify optimal points of feedstock diversification using the concept of Modern Portfolio Theory. Based on the simulation results, we then identify feedstock combinations/portfolios that are on the efficient frontier (Pareto Efficient) and results in the lowest biomass supply variation for a given level of biomass premium. Although diversification may increase the primary feedstock cost (premium), as wheat straw and switchgrass are considered more expensive than corn stover [89-92], the reduction in biomass supply risk could reduce the overall impact on the biorefinery as a result of improved operation efficiency.

Historical yield data (dry t ha-1) of corn stover and wheat straw is used, while for switchgrass we use hay as a proxy for historical data because switchgrass is still under development and there is not enough historical data available that can be used in the simulation. 


\section{Cellulosic biorefinery portfolio and diversification: Strategies to mitigate cellulosic biorefinery risks in US Corn Belt}

This study will provide a framework for developing optimal feedstock diversification portfolios to maximize returns at a given level of risk. The strategies developed through this study can be used together with engineering and logistic options to aid in designing biomass supply chains, devising biorefinery operation plans, and developing national strategies and policy to facilitate the development of a sustainable cellulosic biofuel industry.

Although this study targets the US Corn Belt and its unique feedstock sources, the analytical approach developed here is applicable to other regions with different feedstock sources.

\section{Methods}

\subsection{Concept of Diversification}

The concept of diversification can be explained using the principles of Modern Portfolio Theory [33]. Consider a feedstock supply system with $\mathrm{n}$ different sources of biomass $(\mathrm{j}=1,2,3, \ldots, n)$, where the variance of annual supply of individual feedstock $j$ is $\sigma_{j}^{2}$, its biomass cost is $E_{j}$, and biomass from n sources is mixed in a proportion $w_{j}$ for biomass source $\mathrm{j}$ such that $\sum w_{j}=1$ for all j's to form a feedstock portfolio. The effective cost of the diversified feedstock portfolio is then

$E_{\mathrm{p}}=\sum_{j=0}^{n} w_{\mathrm{j}} E_{\mathrm{j}}$,

and the expected supply variance of the diversified feedstock portfolio is

$\sigma_{\mathrm{p}}{ }^{2}=\sum_{j=0}^{n} \sum_{i=0}^{n} w_{\mathrm{i}} w_{\mathrm{j}} \sigma_{\mathrm{i}} \sigma_{\mathrm{j}} \rho_{\mathrm{ij}}$,

where $\rho_{i j}$ is the correlation coefficient between feedstocks $i$ and $j$, which ranges from +1 to -1 . If the correlation coefficient $\rho_{i j}$ is less than +1.0 , the variance of the diversified feedstock portfolio $\sigma_{p}$ can be reduced to less than the variance of any individual feedstock by mixing them in right proportions. This explains how feedstock diversification can reduce overall feedstock supply variation.

One of the key characteristics of Modern Portfolio Theory is the concept of efficient frontier, defined as a locus of portfolios that offer the highest expected return for a given level of risk or the lowest level of risk for a given level of expected return[33]. Portfolios that are not on the efficient frontier are considered sub-optimal, because they do not provide the highest possible return for the level of risk. Throughout this study we define an efficient frontier as a set of feedstock or biorefinery portfolios that offer the lowest level of risk (overall biomass supply variations) for a given level of biomass premium. 


\section{Cellulosic biorefinery portfolio and diversification: Strategies to mitigate cellulosic biorefinery risks in US Corn Belt}

\subsection{Feedstock diversification}

We define feedstock diversification as a system where a single biorefinery uses a diversified feedstock portfolio, instead of using a single feedstock. In the case of cellulosic biofuels, constraints with long-distance transport and long-term storage of biomass limit feedstock diversification to regional supply boundaries [30].

Research has found that switchgrass, a native perennial grass has the potential as a dedicated energy crop using marginal cropland [34-36], and produces comparable ethanol as corn stover [37]. Since switchgrass grows well in the US Corn Belt as well, it could be used along with corn stover to create a diversified feedstock portfolio. Wheat straw is also abundant in the US Corn Belt, and is another attractive alternative for feedstock diversification [38-41].

A simulation model is created using historical yield data (dry t ha-1) from 2000-2014 to identify variations in corn stover, wheat straw, and switchgrass (hay as a proxy due to switchgrass data limitation). Then the efficient frontier of feedstock diversification is derived for major corn producing states in the US Corn Belt, by optimizing the proportions of corn stover, wheat straw, and switchgrass in the feedstock portfolios.

\subsection{Biorefinery diversification}

Feedstock diversification for a local biorefinery may sometimes be constrained by regional supply characteristics[26,27,30]. For instance, in the US Corn Belt corn stover could be by far the largest and cheapest biomass source [42], while in Brazil, sugarcane waste could be by far the single largest source of most economical biomass [43]. There may also be technological limitations with feedstock diversification as the same biorefinery may be unable to process multiple feedstocks, as feedstock properties and conversion technologies vary [44-48]. Hence, an alternative to feedstock diversification is biorefinery diversification, where a diversified biorefinery portfolio is developed, with biorefineries distributed across multiple locations, and each biorefinery using a single feedstock. Companies that plan on building multiple biorefineries can use this strategy to build a portfolio of diversified cellulosic biorefineries.

While biorefinery diversification may help companies stabilize the total biofuel production and reduce the overall portfolio risk, the capacity of some refinery may not be fully utilized, resulting in efficiency loss. A simulation model is developed to identify the efficient frontier of cellulosic biorefinery portfolios based on corn stover, wheat straw, and switchgrass distributed across the US Corn Belt. 


\section{Cellulosic biorefinery portfolio and diversification: Strategies to mitigate cellulosic biorefinery risks in US Corn Belt}

\subsection{Characterizing biomass yield and supply variations}

The amount of agricultural residues (corn stover and wheat straw) depends on stoverto-grain ratio $\omega$. However, only a portion of stover or straw available at the harvest site is collectable due to equipment limitations, and requirements for retaining soil moisture, preventing soil erosion, and maintaining soil organic carbon (SOC) $[49,50]$. The minimum amount of stover or straw left on the ground $\eta$ (dry $\mathrm{t} \mathrm{ha}^{-1}$ ) is largely dependent on regional characteristics of climate and soil. The amount of collectable stover or straw $P$ is therefore derived as

$P=(Y D \omega-D \eta)$

where $Y$ is crop yield ( $\left.\mathrm{t} \mathrm{ha}^{-1} \mathrm{yr}^{-1}\right)$; and $D$ is the area where the crop is grown (ha).

Stover and straw yield variations are derived respectively using historical data of corn and wheat yields obtained from the US Department of Agriculture (USDA) [51] and converted to metric units based on Graham et al. [42].

Corn Stover Yield: Studies have found that corn stover yield is proportional to corn grain yield, with a stover-to-grain ratio $\omega_{\text {corn }}$ of appropriately 1.0 , and $\eta$ as 5 dry tha-1 [50].

Wheat Straw Yield: We derive collectable wheat straw yield, based on wheat yield and assuming a wheat-to-straw ratio $\omega_{\text {wheat }}$ of 1.3 by weight, and the minimum amount of wheat straw left on the ground as $2.2 \mathrm{dry} \mathrm{t} \mathrm{ha}^{-1}[5,41]$. Cost of delivered wheat straw is considered $10 \%$ higher than that of delivered corn stover, because yield density of wheat straw is less than that of corn stover [40].

Switchgrass: Research on growing switchgrass for bioenergy production is currently under way, and only experimental data of historical yearly yield for switchgrass are available [52]. Furthermore, because the available switchgrass experimental data for the Corn Belt states is an inadequate time series for deriving yearly yield variation, it is not directly used in this analysis. Alternatively we test the correlation between yields for experimental switchgrass with yields of hay for the state of Alabama to check if hay can be used as a proxy for switchgrass. The selection of Alabama is because of its availability of a long time series of data on switchgrass yield. The correlation between the hay and switchgrass yields is found to be statistically significant with a p-value of 0.02(Figure 1). Since hay data is available for the US Corn Belt [51], we use the variations in hay yield for the US Corn Belt as a proxy for its switchgrass yield variations. Biomass cost of switchgrass is assumed 20\% higher than that of corn stover, based on a review of literature $[25,26,30]$. 


\section{Cellulosic biorefinery portfolio and diversification: Strategies to mitigate cellulosic biorefinery risks in US Corn Belt}

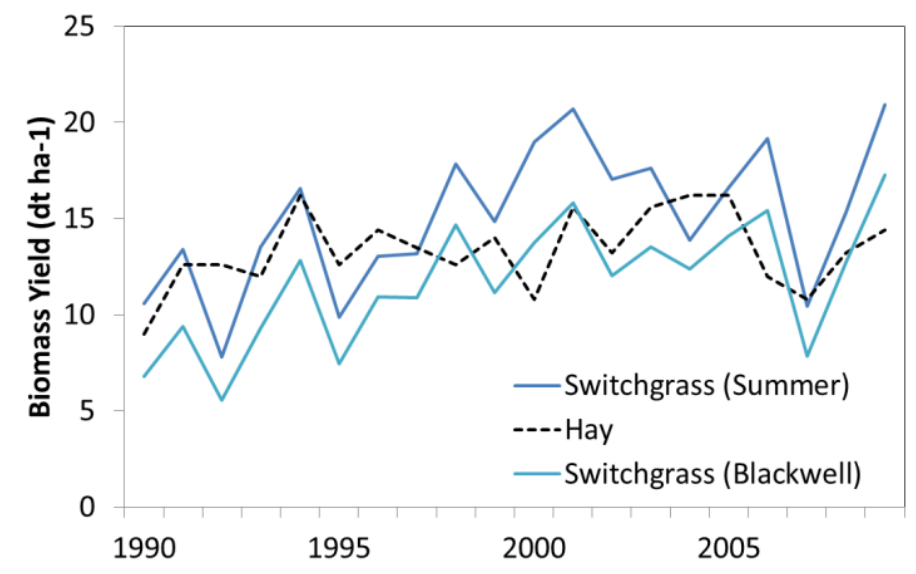

Figure 1. Hay and experimental switchgrass yield. Dotted line is actual hay yield for Alabama, based on USDA data. The blue lines is switchgrass yield for two cultivars in a small-plot experiment in central Alabama [52].

\section{Results}

\subsection{Biomass Supply Variations and Correlations}

Biomass yield density of corn stover, wheat straw, and hay (as proxy for switchgrass) are calculated using equation 3, for the US states of Iowa, Illinois, Nebraska, Indiana, Minnesota, Ohio, Michigan, and Wisconsin.

(a)

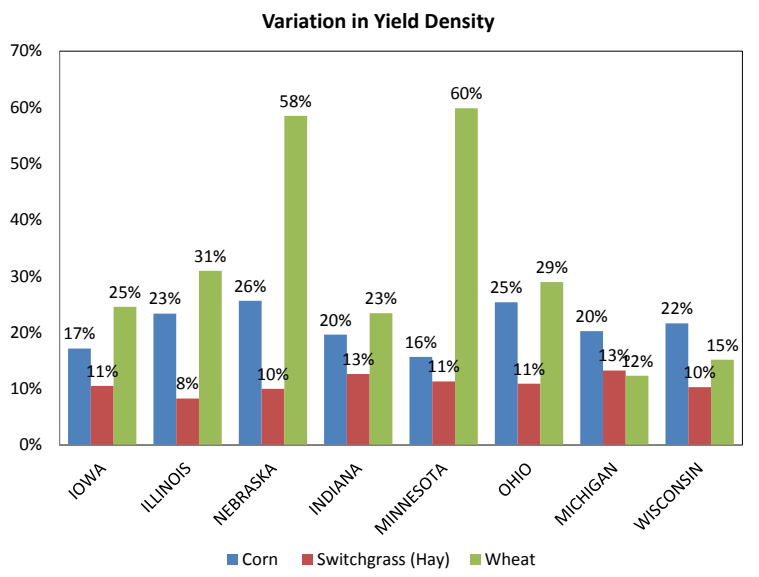

(b)

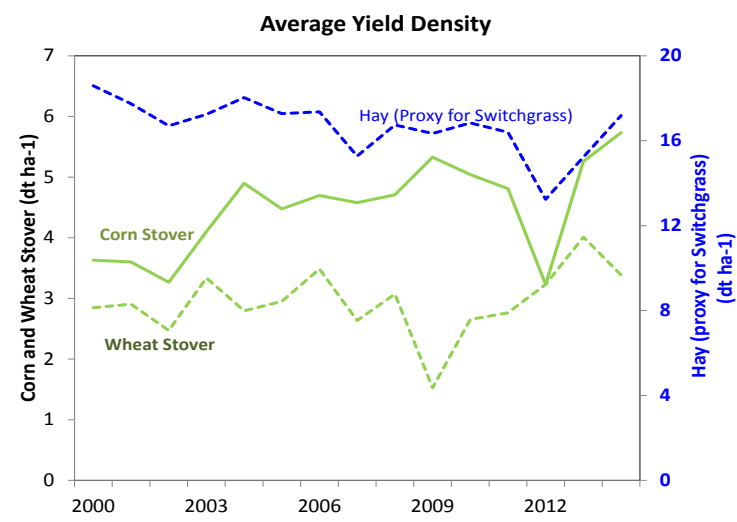

Figure 2. (a) Variation in Corn Stover, Wheat Straw, and Hay Yield Density from 20002014. (b) Average yield density of Corn Stover, Wheat Straw, and Hay from 2000-2014 for the US states in (a). 


\section{Cellulosic biorefinery portfolio and diversification: Strategies to mitigate cellulosic biorefinery risks in US Corn Belt}

Table 1. Biomass supply variation, based on 2000-2014 yield data

\begin{tabular}{|l|l|l|l|}
\hline & Corn Stover & $\begin{array}{l}\text { Hay (proxy for } \\
\text { Switchgrass) }\end{array}$ & Wheat Straw \\
\hline IOWA & $17 \%$ & $11 \%$ & $25 \%$ \\
\hline ILLINOIS & $23 \%$ & $8 \%$ & $31 \%$ \\
\hline NEBRASKA & $26 \%$ & $10 \%$ & $58 \%$ \\
\hline INDIANA & $20 \%$ & $13 \%$ & $23 \%$ \\
\hline MINNESOTA & $16 \%$ & $11 \%$ & $60 \%$ \\
\hline OHIO & $25 \%$ & $11 \%$ & $29 \%$ \\
\hline MICHIGAN & $20 \%$ & $13 \%$ & $12 \%$ \\
\hline WISCONSIN & $22 \%$ & $10 \%$ & $15 \%$ \\
\hline
\end{tabular}

We then define a feedstock system based on feedstock type and location. Correlation between any two systems is calculated (Table 2), and systems that have large negative correlations is identified. Such systems are likely to form lowest variance pairs (Section 2.2.)

Table 2. Correlation between feedstock systems, based on 2000-2014 yield data

\begin{tabular}{|c|c|c|c|c|c|c|c|c|c|c|c|c|c|c|c|c|c|c|c|c|c|c|c|}
\hline & $\begin{array}{l}\frac{\pi}{3} \\
\frac{0}{\dot{v}}\end{array}$ & 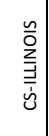 & 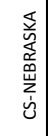 & 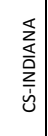 & 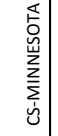 & 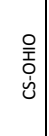 & 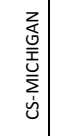 & 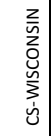 & $\begin{array}{l}\frac{3}{3} \\
0 \\
\dot{j} \\
n\end{array}$ & 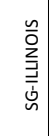 & 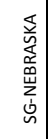 & 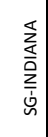 & 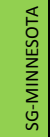 & 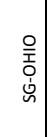 & 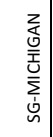 & 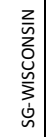 & $\begin{array}{l}\frac{1}{3} \\
\frac{0}{\dot{\omega}} \\
\vdots\end{array}$ & 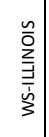 & 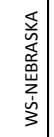 & 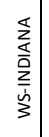 & 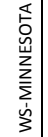 & $\begin{array}{l}\stackrel{0}{\bar{I}} \\
\dot{\omega} \\
\dot{\omega}\end{array}$ & 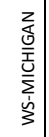 \\
\hline \multicolumn{24}{|l|}{ CS-IOWA } \\
\hline CS-ILLINOIS & 0.6 & & & & & & & & & & & & & & & & & & & & & & \\
\hline CS-NEBRASKA & 0.7 & 0.7 & & & & & & & & & & & & & & & & & & & & & \\
\hline CS-INDIANA & 0.7 & 0.9 & 0.9 & & & & & & & & & & & & & & & & & & & & \\
\hline CS-MINNESOTA & 0.5 & $(0.0)$ & 0.5 & 0.2 & & & & & & & & & & & & & & & & & & & \\
\hline CS-OHIO & 0.4 & 0.7 & 0.7 & 0.8 & \begin{tabular}{l|l}
0.1 \\
\end{tabular} & & & & & & & & & & & & & & & & & & \\
\hline CS-MICHIGAN & 0.6 & 0.4 & 0.7 & 0.5 & \begin{tabular}{l|l}
0.8 \\
\end{tabular} & 0.5 & & & & & & & & & & & & & & & & & \\
\hline CS-WISCONSIN & 0.7 & 0.7 & 0.8 & 0.9 & \begin{tabular}{l|l|}
0.3 \\
\end{tabular} & 0.8 & 0.6 & & & & & & & & & & & & & & & & \\
\hline SG-IOWA & 0.3 & 0.3 & (0.1) & 0.2 & $(0.3)$ & $(0.0)$ & (0.4) & 0.1 & & & & & & & & & & & & & & & \\
\hline SG-ILLINOIS & 0.2 & 0.6 & 0.3 & 0.5 & (0.3) & 0.6 & (0.1) & 0.4 & 0.5 & & & & & & & & & & & & & & \\
\hline SG-NEBRASKA & 0.6 & 0.5 & 0.5 & 0.6 & 0.0 & 0.4 & \begin{tabular}{l|l}
0.1 \\
\end{tabular} & 0.5 & 0.5 & 0.5 & & & & & & & & & & & & & \\
\hline SG-INDIANA & (0.0) & 0.3 & (0.1) & 0.3 & $(0.3)$ & 0.3 & $(0.2)$ & 0.2 & \begin{tabular}{l|l|}
0.6 \\
\end{tabular} & 0.7 & 0.3 & & & & & & & & & & & & \\
\hline SG-MINNESOTA & 0.1 & (0.3) & $(0.3)$ & $(0.2)$ & $(0.1)$ & $(0.2)$ & $(0.3)$ & $(0.0)$ & \begin{tabular}{l|l|}
0.5 \\
\end{tabular} & 0.2 & 0.3 & 0.5 & & & & & & & & & & & \\
\hline SG-OHIO & (0.1) & 0.1 & (0.3) & 0.1 & $(0.3)$ & 0.3 & $(0.3)$ & 0.1 & 0.6 & 0.6 & 0.3 & 0.8 & 0.5 & & & & & & & & & & \\
\hline SG-MICHIGAN & (0.1) & 0.0 & (0.4) & 0.0 & $\begin{array}{l}(0.5) \\
\end{array}$ & (0.1) & $(0.5)$ & 0.1 & \begin{tabular}{l|l|}
0.6 \\
\end{tabular} & 0.5 & 0.0 & 0.7 & 0.6 & 0.7 & & & & & & & & & \\
\hline SG-WISCONSIN & 0.0 & 0.2 & 0.1 & 0.2 & 0.0 & 0.1 & 0.2 & 0.4 & $(0.0)$ & 0.2 & (0.1) & 0.3 & 0.2 & 0.2 & 0.4 & & & & & & & & \\
\hline WS-IOWA & $\begin{array}{l}0.2) \\
\end{array}$ & 0.1 & (0.1) & 0.0 & $\begin{array}{l}(0.3) \\
\end{array}$ & $\begin{array}{ll}0.1 \\
\end{array}$ & $(0.0)$ & $(0.0)$ & $(0.0)$ & 0.2 & $(0.2)$ & 0.3 & $(0.3)$ & (0.1) & 0.1 & (0.1) & & & & & & & \\
\hline WS-ILLINOIS & 0.2 & 0.4 & 0.0 & 0.4 & $(0.3)$ & 0.3 & $(0.1)$ & 0.4 & \begin{tabular}{l|l}
0.6 \\
\end{tabular} & 0.6 & 0.6 & 0.7 & 0.5 & 0.5 & 0.5 & 0.3 & 0.4 & & & & & & \\
\hline WS-NEBRASKA & (0.3) & (0.1) & 0.1 & (0.1) & \begin{tabular}{l|l}
0.1 \\
\end{tabular} & 0.0 & \begin{tabular}{l|l}
0.2 \\
\end{tabular} & $(0.1)$ & $(0.5)$ & $(0.3)$ & (0.5) & (0.3) & (0.7) & (0.4) & $(0.4)$ & $(0.3)$ & 0.6 & $(0.3)$ & & & & & \\
\hline WS-INDIANA & $(0.0)$ & 0.3 & 0.0 & 0.4 & $(0.2)$ & 0.3 & \begin{tabular}{l|l}
0.0 \\
\end{tabular} & 0.3 & 0.3 & 0.5 & 0.4 & 0.7 & 0.2 & 0.6 & 0.4 & 0.4 & 0.4 & 0.8 & 0.1 & & & & \\
\hline WS-MINNESOTA & (0.4) & (0.1) & (0.1) & $(0.2)$ & $(0.0)$ & 0.0 & \begin{tabular}{l|l}
0.1 \\
\end{tabular} & $(0.3)$ & $(0.5)$ & $(0.3)$ & (0.5) & (0.2) & (0.6) & (0.4) & $(0.4)$ & $(0.3)$ & 0.5 & (0.4) & 0.9 & 0.0 & & & \\
\hline WS-OHIO & (0.5) & $(0.2)$ & (0.3) & $(0.2)$ & $\begin{array}{l}(0.1) \\
\end{array}$ & $(0.2)$ & \begin{tabular}{l|l}
0.0 \\
\end{tabular} & $(0.3)$ & $(0.3)$ & (0.3) & (0.4) & 0.1 & $(0.3)$ & (0.1) & (0.1) & 0.1 & 0.6 & 0.0 & 0.7 & \begin{tabular}{l|l|}
0.5 \\
\end{tabular} & $\begin{array}{ll}0.7 \\
\end{array}$ & & \\
\hline WS-MICHIGAN & 0.1 & 0.2 & 0.1 & 0.2 & 0.2 & 0.3 & \begin{tabular}{l|l}
0.3 \\
\end{tabular} & 0.6 & (0.1) & 0.2 & 0.1 & 0.2 & 0.4 & 0.3 & 0.4 & 0.7 & $(0.1)$ & 0.5 & (0.4) & $\begin{array}{ll}0.3 \\
\end{array}$ & (0.5) & $(0.2)$ & \\
\hline WS-WISCONSIN & (0.2) & 0.3 & 0.1 & 0.2 & $(0.2)$ & 0.3 & 0.2 & 0.3 & $(0.2)$ & 0.1 & (0.1) & 0.0 & (0.4) & (0.1) & 0.0 & 0.1 & 0.7 & 0.4 & 0.4 & \begin{tabular}{l|l}
0.4 \\
\end{tabular} & 0.3 & \begin{tabular}{l|l}
0.4 \\
\end{tabular} & 0.3 \\
\hline
\end{tabular}

CS: Corn Stover; SG: Switchgrass (proxy by hay); WS: Wheat Straw 


\section{Cellulosic biorefinery portfolio and diversification: Strategies to mitigate cellulosic biorefinery risks in US Corn Belt}

\subsection{Feedstock diversification}

The impact of feedstock diversification using corn stover, wheat straw, and switchgrass is evaluated. We simulate by assigning different proportions of each of the three feedstocks. Using risk (biomass supply variation) vs. premium (biomass supply cost), an efficient frontier is developed that results in the lowest supply variation at a given premium. Results for the state of Iowa are shown in Figure 3. The biomass ratio (i.e., corn stover : wheat straw : switchgrass) along the Efficient Frontier represents the optimal level of diversification that minimizes overall biomass cost for a given level of risk tolerance. While the green star in Figure 3 represents the point of minimum supply variations, a biorefinery may choose to operate at any point on the efficient frontier, depending on its risk tolerance and strategy.

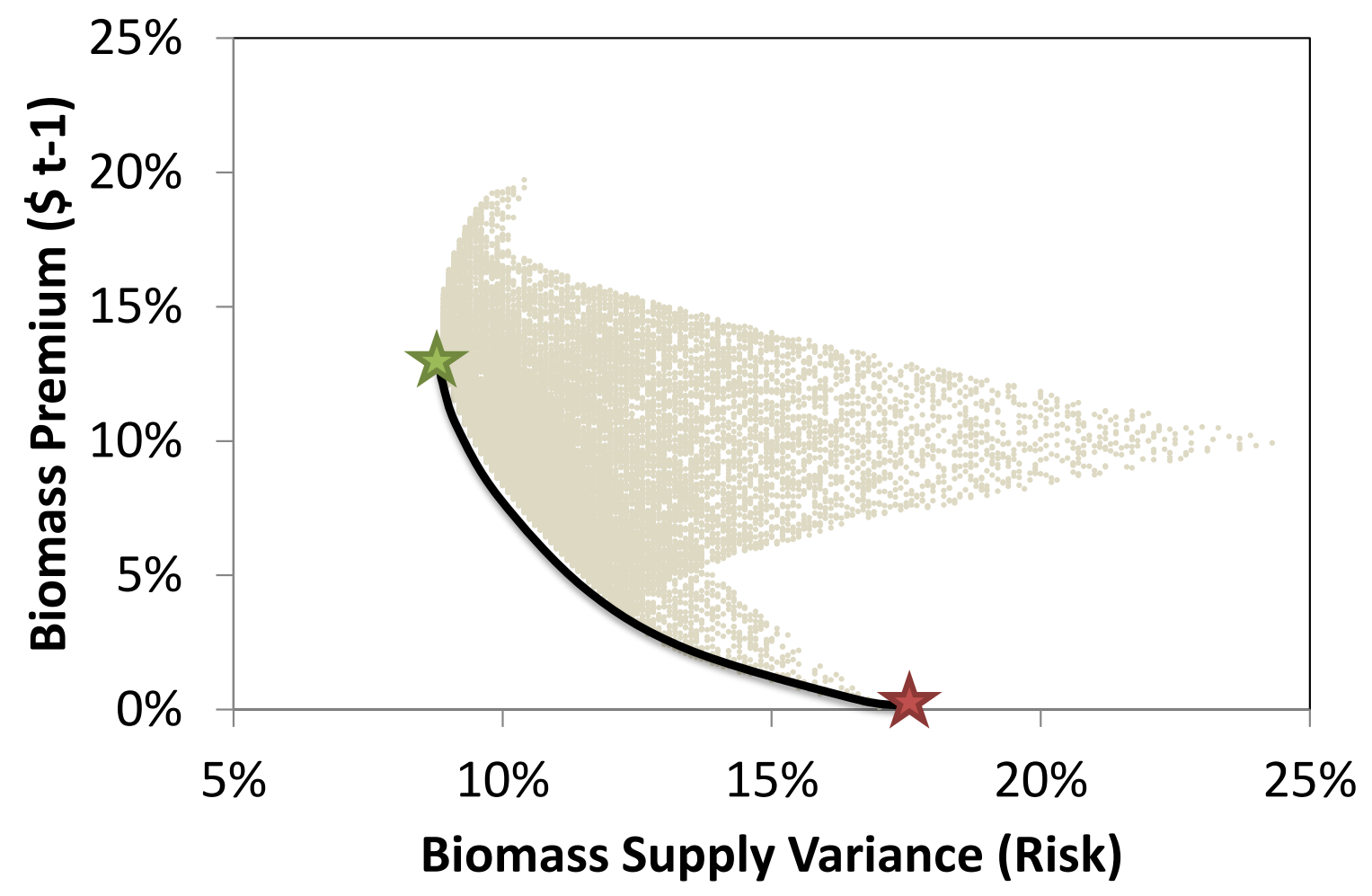

Figure 3. Feedstock diversification for the state of Iowa. The red star indicates the point of $100 \%$ corn stover, and the green star indicates the point of minimum supply variance achieved through diversification of corn stover with wheat straw and switchgrass.

Based on simulation results, the minimum biomass supply variation for the state of Iowa is achieved when corn stover, wheat straw, and switchgrass are mixed in a ratio of 50:25:25. The increase in biomass cost (premium) for this portfolio is $9 \%$, compared with $100 \%$ corn stover while supply variations reduce from $17 \%$ for corn stove only to $10 \%$ for the diversified feedstock (a $40 \%$ reduction in feedstock supply variation). The 


\section{Cellulosic biorefinery portfolio and diversification: Strategies to mitigate cellulosic biorefinery risks in US Corn Belt}

increase in biomass cost is because the costs of delivered wheat straw and switchgrass are assumed $10 \%$ and $20 \%$ higher than those of corn stover, respectively.

For the state of Wisconsin the mix of corn stover: wheat straw : switchgrass that results in the lowest biomass variation is 45:25:35. The premium for the feedstock diversification is $9 \%$, and the resulting biomass supply variation reduces from $22 \%$ to $12 \%$. Feedstock diversification for Illinois resulting in the lowest biomass supply variation is at the biomass ratio of 40:10:50, in which reduces the overall feedstock supply variation from $23 \%$ to $13 \%$ at a premium of $11 \%$. Table 3 summarizes these results along the efficient frontiers for other US Corn Belt states.

Table 3. Biomass supply variation between single feedstock (corn stover) and the diversified feedstock portfolio with the minimal variation at the Efficient Frontier

\begin{tabular}{|c|c|c|c|c|c|c|}
\hline \multirow[t]{2}{*}{ State } & \multirow{2}{*}{$\begin{array}{l}\text { Undiversified } \\
\text { Feedsock } \\
\text { (Corn Stover) } \\
\text { Variation (\%) }\end{array}$} & \multirow{2}{*}{$\begin{array}{l}\text { Diversified } \\
\text { Feedstock } \\
\text { Variation } \\
\text { (Min } \\
\text { Variation) } \\
(\%)\end{array}$} & \multirow{2}{*}{$\begin{array}{l}\text { Premium at } \\
\text { Min } \\
\text { Variation } \\
(\%)\end{array}$} & \multicolumn{3}{|c|}{$\begin{array}{l}\text { Feedstock Mix Ratio at Min } \\
\text { Variation (\%) }\end{array}$} \\
\hline & & & & $\begin{array}{l}\text { Corn } \\
\text { Stover }\end{array}$ & $\begin{array}{l}\text { Wheat } \\
\text { Straw }\end{array}$ & $\begin{array}{l}\text { Switch- } \\
\text { grass* }\end{array}$ \\
\hline Iowa & 17 & 10 & 7 & 50 & 25 & 25 \\
\hline Illinois & 23 & 13 & 11 & 40 & 10 & 50 \\
\hline Nebraska & 26 & 14 & 10 & 40 & 10 & 50 \\
\hline Indiana & 20 & 13 & 10 & 45 & 10 & 45 \\
\hline Minnesota & 16 & 8 & 9 & 50 & 10 & 40 \\
\hline Ohio & 25 & 13 & 9 & 45 & 15 & 40 \\
\hline Michigan & 20 & 9 & 10 & 45 & 15 & 40 \\
\hline Wisconsin & 22 & 12 & 9 & 45 & 25 & 35 \\
\hline Average & 21 & 12 & 9 & 45 & 15 & 40 \\
\hline
\end{tabular}

*Variations are based on hay, due to lack of historical data for switchgrass.

The resultant change in biorefinery profit as a result of reduced biomass supply variations will depend on biomass supply market structure, biorefinery size, and biofuel price, among other things. The locus on the efficient frontier with the lowest overall 


\section{Cellulosic biorefinery portfolio and diversification: Strategies to mitigate cellulosic biorefinery risks in US Corn Belt}

biomass variation may not be the most optimal point of operation for a biorefinery if the increase in biomass cost (premium) as a result of diversification cannot be offset by improved overall efficiency of the biofuel supply chain. The improvement on the overall efficiency of a biofuel supply chain is complex and thus subject for future endeavour. Nevertheless, our results reveal the trade-offs between feedstock diversification and feedstock cost, important knowledge for designing the logistic system and operation strategy of a biofuel supply chain.

\subsection{Biorefinery diversification}

Here we identify combinations of feedstock and biorefinery location and simulate the impact on overall biomass supply variation and cost. The results of simulations are shown in Figure 4.

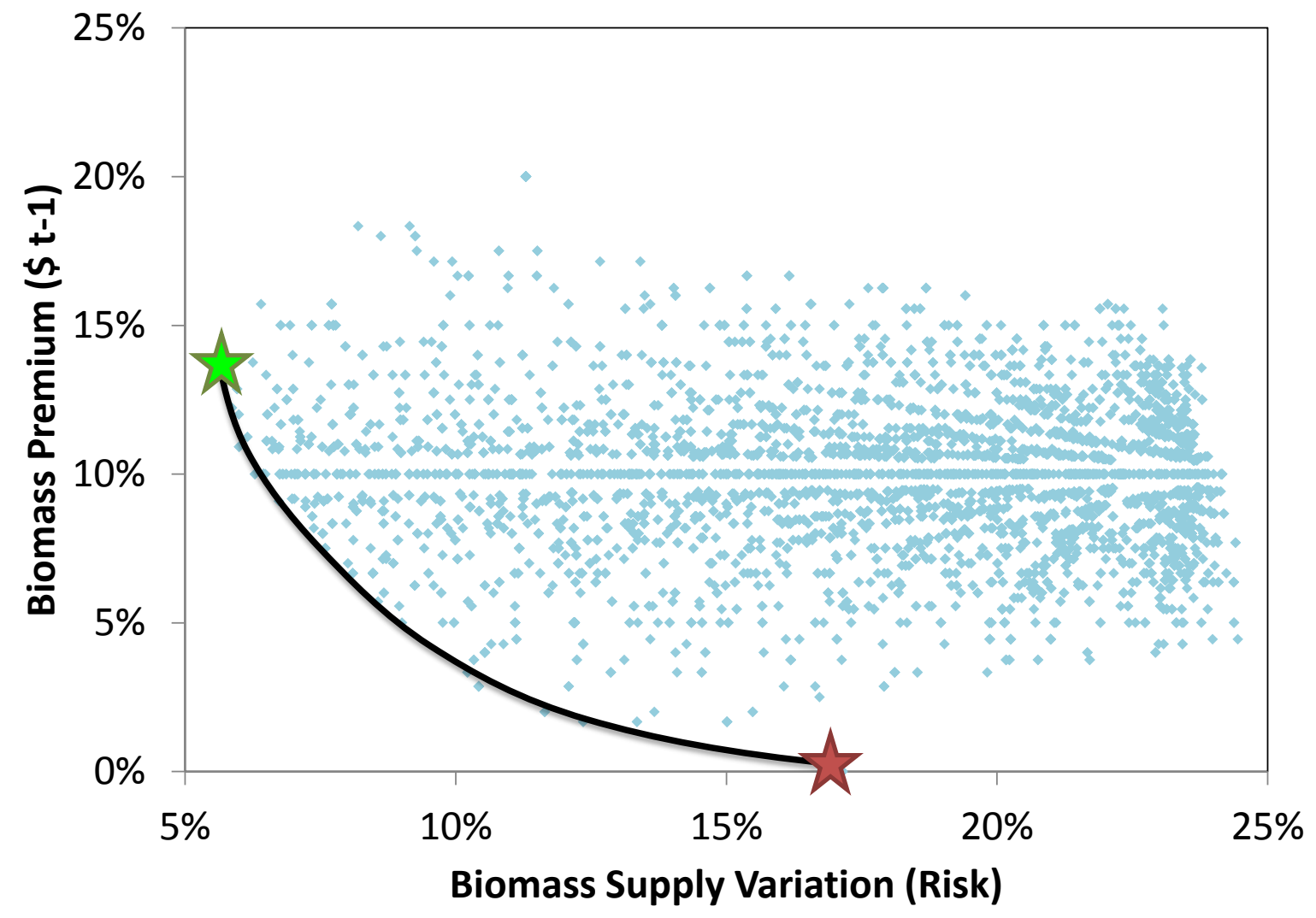

Figure 4. Biorefinery diversification and efficient frontier. The red star indicates the point of $100 \%$ corn stover, and the green star indicates the point of minimum supply variance achieved through diversification of biorefineries by location and feedstock type. The black line is the efficient frontier.

Based on the simulation results, the minimum biomass supply variation is reached when the biorefinery portfolio consists of $40-50 \%$ corn stover based biorefineries, 40 - 


\section{Cellulosic biorefinery portfolio and diversification: Strategies to mitigate cellulosic biorefinery risks in US Corn Belt}

$50 \%$ switchgrass based biorefineries, and $10-20 \%$ wheat straw based biorefineries distributed across different states of the US Corn Belt. This portfolio results in overall risk from regional biomass supply variation of just around $6 \%$, compared to the average variation in corn stover supply of around $17 \%$. The biomass premium (cost increase) for such a portfolio is approximately $9 \%$. Although the overall portfolio risk is significantly reduced, some biorefineries may not be operated under full capacity in some years.

\subsection{Summary of Results}

The results of single feedstock, feedstock diversification, and biorefinery diversification at the regional level are plotted in Figure 5. These results show that biorefinery diversification is an effective way of managing biomass supply variations at the regional level. However, this will require that each of the three feedstocks is grown in relatively concentrated and large enough areas. This is unlikely due to competing use of agricultural land in the region. The second most effective way to mitigate feedstock supply variation is to use multiple feedstocks in a biorefinery. This seems more practical in terms of land use patterns though the feedstock logistic system and biomass-tobiofuel conversion technology are required to be able to handle multiple types of feedstocks.

\section{Biomass Supply Variation vs. Premium}

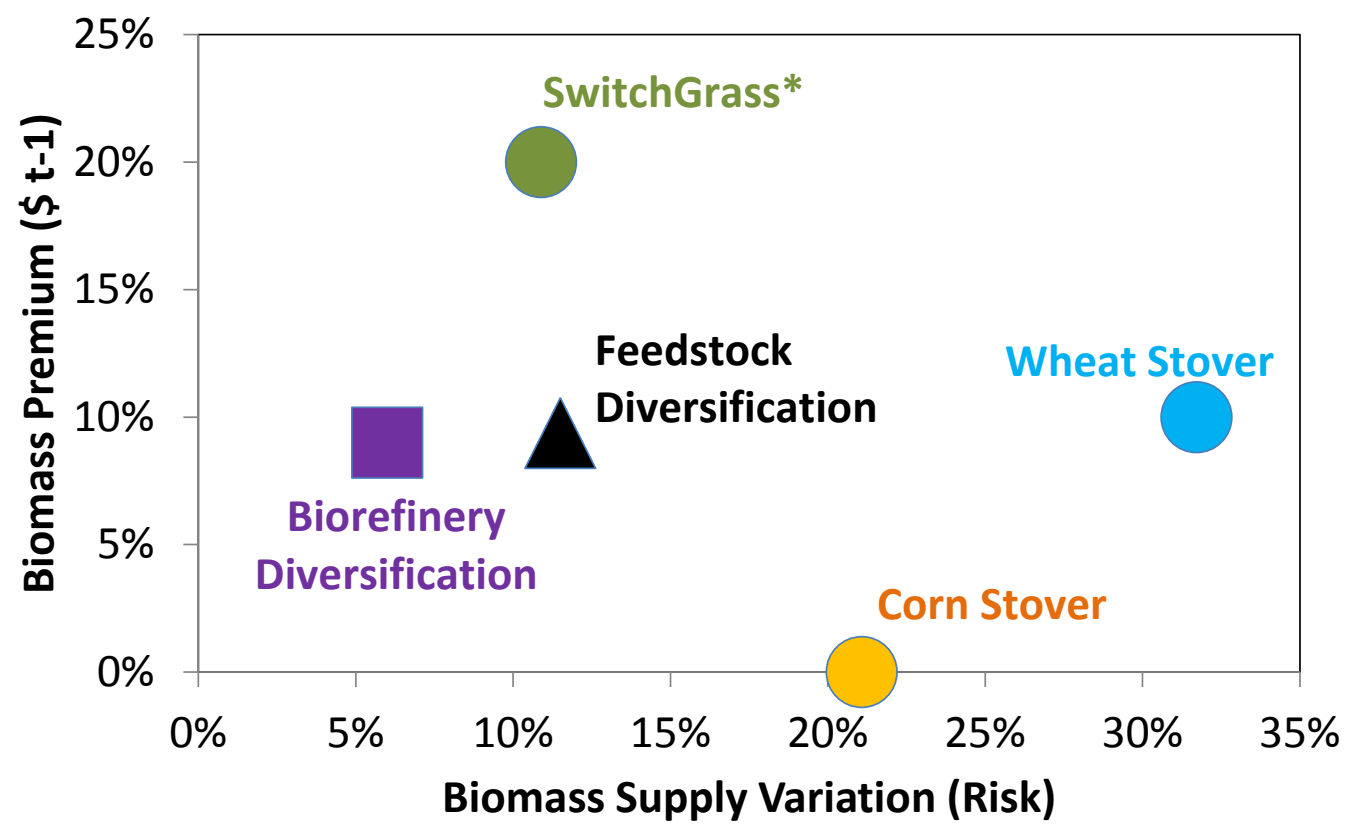

Figure 5: Biomass supply variation vs. premium under single feedstock, feedstock diversification, and biorefinery diversification. The points for feedstock diversification and biorefinery diversification are at the lowest biomass supply variance on the efficient frontier (Figures 3 and 4). 


\section{Cellulosic biorefinery portfolio and diversification: Strategies to mitigate cellulosic biorefinery risks in US Corn Belt}

\section{Conclusions}

Large variations in cellulosic biomass supply are a major issue for sustainable development of a cellulosic biofuel industry due to limitations associated with longdistance transport and long-term storage of biomass. In the absence of strategies to minimize the impact of these variations, biorefineries venturing in the cellulosic biofuel industry will be significantly exposed. We find that feedstock diversification and biorefinery diversification are very effective strategies for mitigating the impact of these variations. Feedstock diversification means feeding an individual biorefinery with multiple (diversified) feedstocks. Biorefinery diversification means building a cellulosic biorefinery portfolio consisting of diversified biorefinery locations and feedstock types, while still feeding an individual biorefinery with a single feedstock type. Simulating the effect of diversification in the US Corn Belt using corn stover, wheat straw, and switchgrass, an efficient frontier is derived using the principle of Modern Portfolio Theory that minimizes biomass supply variation at a given biomass premium.

It is found that feedstock diversification of corn stover with wheat straw and switchgrass could reduce variations in the aggregate collectable biomass supply by more than $40 \%$ (from $20-25 \%$ to $10-15 \%$ ), while increasing the biomass cost by only $9-10 \%$. The biomass cost hike is largely because switchgrass is assumed to be $20 \%$ more costly than corn stover. Advancements in switchgrass research and development to reduce its production cost could further enhance the advantage of using switchgrass to mitigate year-to-year supply variations in corn stover. Variations in feedstock are found to vary by state, and accordingly the optimal ratio of corn stover: wheat straw: switchgrass that creates the Efficient Frontier varies by state. Overall, the optimal ratio to achieve the minimum biomass variation is found to be $45: 15: 40$ at a biomass premium of $12 \%$ for the US Corn Belt region.

Biorefinery diversification is found to be a relatively more effective strategy as a 70\% reduction in regional biomass supply variation could be achieved (20-25\% to 6-7\%), with an equivalent increase in premium (9-10\%). Based on simulation results, the minimum biomass supply variation through biorefinery diversification in the US Corn Belt is reached when the portfolio consists of 4-5 corn stover based biorefineries, 4-5 switch grass based biorefineries, and 1-2 wheat straw based biorefineries, distributed across different Corn Belt states. Yet, this option may not be practical for the region due to competing uses of agricultural land and the fact that grain prices rather than stover or straw price determine cropland use or crop area planted and ultimately crop residue availability.

The level of risk in biomass supply variation that a biorefinery is willing to accept will depend on the fundamental business strategy of the biorefinery, and the biomass premium it is willing to pay. The efficient frontier provides the optimal proportions of different feedstocks that result in the lowest variation in overall biomass supply for a given biomass premium. 


\section{Cellulosic biorefinery portfolio and diversification: Strategies to mitigate cellulosic biorefinery risks in US Corn Belt}

While biorefinery diversification is one of the most effective ways of mitigating biomass supply variations, its scope is limited to companies that plan on building multiple biorefineries. Further studies are needed to understand the loss in economics of scale due to biorefinery diversification. On the other hand, constraints with feedstock diversification could be additional capital investments needed to enable biorefineries to process multiple feedstocks. Biomass supply market strategies and contracts between biorefineries and farmers could be another effective way of mitigating biomass supply variations although it is beyond the scope of this study. Additionally, feedstock and biorefinery diversification strategies can coupled with engineering options such as feedstock pre-treatment and storage to mitigate biomass supply variations. A call for examining these additional strategies is in order.

\section{References}

[1] S. Pohit, P.K. Biswas, R. Kumar, J. Jha, International experiences of ethanol as transport fuel: Policy implications for India, Energy Policy. 37 (2009) 4540-4548. doi:10.1016/j.enpol.2009.06.010.

[2] M.Q. Wang, J. Han, Z. Haq, W.E. Tyner, M. Wu, A. Elgowainy, Energy and greenhouse gas emission effects of corn and cellulosic ethanol with technology improvements and land use changes, Biomass and Bioenergy. 35 (2011) 1885-1896. doi:10.1016/j.biombioe.2011.01.028.

[3] R.E.H. Sims, W. Mabee, J.N. Saddler, M. Taylor, An overview of second generation biofuel technologies, Bioresour. Technol. 101 (2010) 1570-1580. doi:10.1016/j.biortech.2009.11.046.

[4] Biomass Research and Development Initiative (BRDI), Increasing feedstock production for biofuels: economic drivers, environmental implications, and the role of research. Washington, DC. 146 pp., 2008.

[5] A.F. Turhollow, R.D. Perlack, L.M. Eaton, M.H. Langholtz, C.C. Brandt, M.E. Downing, et al., The Updated Billion-Ton Resource Assessment, Biomass and Bioenergy. 70 (2014) 149-164. doi:10.1016/j.biombioe.2014.09.007.

[6] R. Golecha, J. Gan, Effects of corn stover year-to-year supply variability and market structure on biomass utilization and cost, Renew. Sustain. Energy Rev. 57 (2016) 34-44. doi:10.1016/j.rser.2015.12.075.

[7] R. Golecha, J. Gan, Optimal contracting structure between cellulosic biorefi neries and farmers to reduce the impact of biomass supply variation: game theoretic analysis, Biofuels, Bioprod. Biorefining. (2016) 246-256. doi:10.1002/bbb.1626.

[8] I. Awudu, J. Zhang, Uncertainties and sustainability concepts in biofuel supply chain management: A review, Renew. Sustain. Energy Rev. 16 (2012) 1359-1368. doi:10.1016/j.rser.2011.10.016.

[9] K. Theerarattananoon, F. Xu, J. Wilson, R. Ballard, L. Mckinney, S. Staggenborg, et al., Physical properties of pellets made from sorghum stalk, corn stover , wheat straw , and big bluestem, 33 (2011) 325-332. doi:10.1016/j.indcrop.2010.11.014.

[10] A. Uslu, A. Faaij, Pre-treatment technologies , and their effect on international bioenergy supply chain logistics . Techno-economic evaluation of torrefaction , fast pyrolysis and pelletisation, 33 (2008) 1206-1223. doi:10.1016/j.energy.2008.03.007. 


\section{Cellulosic biorefinery portfolio and diversification: Strategies to mitigate cellulosic biorefinery risks in US Corn Belt}

[11] N. Kaliyan, R.V. Morey, Factors affecting strength and durability of densified biomass products, Biomass and Bioenergy. 33 (2009) 337-359. doi:10.1016/j.biombioe.2008.08.005.

[12] A. Karamchandani, H. Yi, V.M. Puri, Fundamental mechanical properties of ground switchgrass for quality assessment of pellets, Powder Technol. 283 (2015) 48-56. doi:10.1016/j.powtec.2015.04.069.

[13] J.S. Tumuluru, Effect of process variables on the density and durability of the pellets made from high moisture corn stover, Biosyst. Eng. 119 (2014) 44-57. doi:10.1016/j.biosystemseng.2013.11.012.

[14] A.A. Rentizelas, A.J. Tolis, I.P. Tatsiopoulos, Logistics issues of biomass: The storage problem and the multi-biomass supply chain, Renew. Sustain. Energy Rev. 13 (2009) 887-894. doi:10.1016/j.rser.2008.01.003.

[15] I. Awudu, J. Zhang, Stochastic production planning for a biofuel supply chain under demand and price uncertainties, Appl. Energy. 103 (2013) 189-196. doi:10.1016/j.apenergy.2012.09.025.

[16] Q. Li, G. Hu, Supply chain design under uncertainty for advanced biofuel production based on biooil gasi fi cation, Energy. 74 (2014) 576-584. doi:10.1016/j.energy.2014.07.023.

[17] Y.E. Huang, Y. Fan, C. Chen, Y.E. Huang, Y. Fan, C. Chen, An Integrated Biofuel Supply Chain to Cope with Feedstock Seasonality and Uncertainty An Integrated Biofuel Supply Chain to Cope with Feedstock Seasonality and Uncertainty, Transp. Sci. 48 (2014) 540-554.

[18] J. Ren, L. Dong, L. Sun, M. Evan, S. Tan, L. Dong, Life cycle cost optimization of biofuel supply chains under uncertainties based on interval linear programming, Bioresour. Technol. 187 (2015) 6-13. doi:10.1016/j.biortech.2015.03.083.

[19] M. Dal-mas, S. Giarola, A. Zamboni, F. Bezzo, Strategic design and investment capacity planning of the ethanol supply chain under price uncertainty, Biomass and Bioenergy. 35 (2011) 2059-2071. doi:10.1016/j.biombioe.2011.01.060.

[20] K. Tong, M. Joseph, G. Rong, F. You, ScienceDirect Optimal design of advanced drop-in hydrocarbon biofuel supply chain integrating with existing petroleum refineries under uncertainty, Biomass and Bioenergy. 60 (2013) 108-120. doi:10.1016/j.biombioe.2013.10.023.

[21] M. Sharifzadeh, M.C. Garcia, N. Shah, Biomass and Bioenergy Supply chain network design and operation : Systematic decision- making for centralized, distributed, and mobile biofuel production using mixed integer linear programming ( MILP) under uncertainty, Biomass and Bioenergy. 81 (2015) 401-414. doi:10.1016/j.biombioe.2015.07.026.

[22] B.D. Bals, B.E. Dale, Developing a model for assessing biomass processing technologies within a local biomass processing depot, Bioresour. Technol. 106 (2012) 161-169. doi:10.1016/j.biortech.2011.12.024.

[23] E. Gülşen, E. Olivetti, F. Freire, L. Dias, R. Kirchain, Impact of feedstock diversification on the costeffectiveness of biodiesel, Appl. Energy. 126 (2014) 281-296. doi:10.1016/j.apenergy.2014.03.063.

[24] S.W. Hasan, M.T. Ghannam, N. Esmail, Heavy crude oil viscosity reduction and rheology for pipeline transportation, Fuel. 89 (2010) 1095-1100. doi:10.1016/j.fuel.2009.12.021.

[25] M. Duffy, Estimated Costs for Production, Storage, and Transportation of Switchgrass, 2008. doi:www.extension.iastate.edu/agdm Estimated. 


\section{Cellulosic biorefinery portfolio and diversification: Strategies to mitigate cellulosic biorefinery risks in US Corn Belt}

[26] S. Brechbill, W.E. Tyner, The economics of renewable energy: corn stover and switchgrass, 2008. http://www.ces.purdue.edu/bioenergy.

[27] M. Carriquiry, X. Du, G.R. Timilsina, Second generation biofuels: Economics and policies, Energy Policy. 39 (2011) 4222-4234. doi:10.1016/j.enpol.2011.04.036.

[28] J.R. Hettenhaus, R. Wooley, A. Wiselogel, Biomass Commercialization Prospects in the Next 2-5 Years, 2000.

[29] A.D. Maker, Estimating a Value for Corn Stover, Iowa State Univ. Extension, Ag Decis. Mak. Doc. FM-1698. (2007) 4-7.

[30] D.R. Petrolia, The economics of harvesting and transporting corn stover for conversion to fuel ethanol: A case study for Minnesota, Biomass and Bioenergy. 32 (2008) 603-612. doi:10.1016/j.biombioe.2007.12.012.

[31] R. Golecha, J. Gan, Biomass transport cost when biomass yield density and road network vary with transport radius, Appl. Energy. (n.d.) 1-14.

[32] J. Gan, C.T. Smith, Optimal plant size and feedstock supply radius: A modeling approach to minimize bioenergy production costs, Biomass and Bioenergy. 35 (2011) 3350-3359. doi:10.1016/j.biombioe.2010.08.062.

[33] B. Blackwell, Illustrative Portfolio Analysis, in: Portf. Sel. Effic. Diversif. INVESTMENTS, Wiley, Yale University Press, 1959.

[34] M.A. Sanderson, R.L. Reed, S.B. McLaughlin, S.D. Wullschleger, B. V. Conger, D.J. Parrish, et al., Switchgrass as a sustainable bioenergy crop, in: Bioresour. Technol., 1996: pp. 83-93. doi:10.1016/0960-8524(95)00176-X.

[35] S.B. McLaughlin, L.A. Kszos, Development of switchgrass (Panicum virgatum) as a bioenergy feedstock in the United States, Biomass and Bioenergy. 28 (2005) 515-535. doi:10.1016/j.biombioe.2004.05.006.

[36] A. Kumar, S. Sokhansanj, Switchgrass (Panicum vigratum, L.) delivery to a biorefinery using integrated biomass supply analysis and logistics (IBSAL) model, Bioresour. Technol. 98 (2007) 1033-1044. doi:10.1016/j.biortech.2006.04.027.

[37] G.E. Varvel, K.P. Vogel, R.B. Mitchell, R.F. Follett, J.M. Kimble, Comparison of corn and switchgrass on marginal soils for bioenergy, Biomass and Bioenergy. 32 (2008) 18-21. doi:10.1016/j.biombioe.2007.07.003.

[38] T.A. Maung, C.R. Gustafson, D.M. Saxowsky, J. Nowatzki, T. Miljkovic, D. Ripplinger, The logistics of supplying single vs. multi-crop cellulosic feedstocks to a biorefinery in southeast North Dakota, Appl. Energy. 109 (2013) 229-238. doi:10.1016/j.apenergy.2013.04.003.

[39] R.G. Nelson, Resource assessment and removal analysis for corn stover and wheat straw in the Eastern and Midwestern United states - Rainfall and wind-induced soil erosion methodology, Biomass and Bioenergy. 22 (2002) 349-363. doi:10.1016/S0961-9534(02)00006-5.

[40] R.D. Perlack, B.J. Stokes, L.M. Eaton, A.F. Turnhollow, U.S. Billion-Ton Update, 2011. https://bioenergykdf.net/.

[41] F. Talebnia, D. Karakashev, I. Angelidaki, Production of bioethanol from wheat straw: An overview on pretreatment, hydrolysis and fermentation, Bioresour. Technol. 101 (2010) 4744-4753. doi:10.1016/j.biortech.2009.11.080. 


\section{Cellulosic biorefinery portfolio and diversification: Strategies to mitigate cellulosic biorefinery risks in US Corn Belt}

[42] R.L. Graham, R. Nelson, J. Sheehan, R.D. Perlack, L.L. Wright, Current and potential U.S. corn stover supplies, Agron. J. 99 (2007) 1-11. doi:10.2134/agronj2005.0222.

[43] C.T. Hotta, C.G. Lembke, D.S. Domingues, E.A. Ochoa, G.M.Q. Cruz, D.M. Melotto-Passarin, et al., The biotechnology roadmap for sugarcane improvement, Trop. Plant Biol. 3 (2010) 75-87. doi:10.1007/s12042-010-9050-5.

[44] L. Luo, E. van der Voet, G. Huppes, Biorefining of lignocellulosic feedstock--Technical, economic and environmental considerations., Bioresour. Technol. 101 (2010) 5023-5032. doi:10.1016/j.biortech.2009.12.109.

[45] P. Kaparaju, M. Serrano, A.B. Thomsen, P. Kongjan, I. Angelidaki, Bioethanol, biohydrogen and biogas production from wheat straw in a biorefinery concept, Bioresour. Technol. 100 (2009) 2562-2568. doi:10.1016/j.biortech.2008.11.011.

[46] J. Moncada, M.M. El-Halwagi, C.A. Cardona, Techno-economic analysis for a sugarcane biorefinery: Colombian case, Bioresour. Technol. 135 (2013) 533-543. doi:10.1016/j.biortech.2012.08.137.

[47] M. Haque, F.M. Epplin, Cost to produce switchgrass and cost to produce ethanol from switchgrass for several levels of biorefinery investment cost and biomass to ethanol conversion rates, Biomass and Bioenergy. 46 (2012) 517-530. doi:10.1016/j.biombioe.2012.07.008.

[48] D.H.S. Tay, D.K.S. Ng, H. Kheireddine, M.M. El-Halwagi, Synthesis of an integrated biorefinery via the C-H-O ternary diagram, Clean Technol. Environ. Policy. 13 (2011) 567-579. doi:10.1007/s10098-011-0354-4.

[49] W.W. Wilhelm, J.M.F. Johnson, D.L. Karlen, D.T. Lightle, Corn stover to sustain soil organic carbon further constrains biomass supply, Agron. J. 99 (2007) 1665-1667. doi:10.2134/agronj2007.0150.

[50] W.W. Wilhelm, J.M.F. Johnson, D.T. Lightle, D.L. Karlen, J.M. Novak, N.W. Barbour, et al., Vertical distribution of corn stover dry mass grown at several US locations, Bioenergy Res. 4 (2011) 1121. doi:10.1007/s12155-010-9097-z.

[51] USDA, Crop Production Historical Track Records, 2013.

[52] D. Bransby, P. Huang, Twenty-Year Biomass Yields of Eight Switchgrass Cultivars in Alabama, Bioenergy Res. 7 (2014) 1186-1190. doi:10.1007/s12155-014-9448-2.

\section{Acknowledgement}

This work was supported in part by funding from the U.S. Department of Energy's Office of Energy Efficiency and Renewable Energy, Bioenergy Technologies Office and Office of International Affairs under award number DE-PI0000031 and from the U.S. Department of Agriculture's National Institute of Food and Agriculture under award number 2012-67009-19742 and Mclntire-Stennis Program. However, opinions expressed here do not reflect those of the funding agencies. 